\title{
Integrating nutrition with ecology: balancing the health of humans and biosphere
}

\author{
Anthony J McMichael* \\ National Centre for Epidemiology and Population Health, \\ The Australian National University, Canberra, Australia
}

\begin{abstract}
Objective: To show that current rates of global population growth, production and consumption of food, and use of living and physical resources, are evidently not sustainable. To consider ways in which nutrition and allied sciences can respond to this great challenge of the twenty-first century.

Method: Past, current and future projected trends in production and consumption patterns are examined. These show that overall present and projected patterns cannot be sustained; and also show increasing unacceptable inequity between and within rich and poor regions and countries.

Discussion: Nutrition science classically focuses on nutrients in relation to human physiology, metabolism, growth, health and disease. The social and environmental conditions of the modern, interconnected, market-oriented world, and the consequences for food production and consumption, are extending the research and policy agenda with which nutrition science must now urgently engage. Historically, much attention has been paid to eliminating nutritional deficiency states, and this remains an important task. In modern urban populations 'malnutrition' encompasses new forms of dietary imbalance, especially excesses of certain nutrients. These contribute to various non-communicable diseases and, particularly, to overweight/obesity and its attendant metabolic derangements and disease risks. As a mass phenomenon the current surge in obesity has no historical precedent. The escalating impact of humankind on the natural environment, with its ramifications for present and future food production, is also unprecedented.

Conclusion: The essential challenge for nutrition science is to develop new understanding and strategies to enable a balance between promoting, equitably, the health of humans while sustaining the long-term health of the biosphere. Extension of nutrition science and food policy to meet those goals will be aided by understanding better how dietary conditions shaped the biological evolution of humankind. The fundamental long-term task is to integrate human health with the health of the biosphere.
\end{abstract}

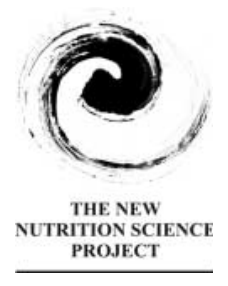

PROJECT

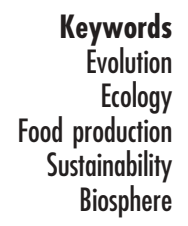

Nutrition science as conventionally practised studies the nutrient needs of human biology for growth and health, and the risks of dysfunction and disease due to inappropriate nutrient intake. This body of knowledge has been built up by empirical research, both animalexperimental and human-epidemiological. That research has typically employed a reductionist cause-and-effect approach (reflecting the proud foundations of Western science). I argue here that we need to extend that frame, to engage with a larger, systems-based, understanding of nutrition and the ecology of food production.

Food policy must, in the first instance, implement policies that support the production and consumption of health-promoting foods and that also seek equitable access to those foods. Policies to support health-promoting food can be enriched by understanding the diet-related pressures that shaped the biological evolution of the hominid line and, eventually, Homo sapiens. This process has equipped human biology for a diet that supplies an appropriate balance of nutrients and a total energy intake commensurate with the energy required for daily living. Yes, we are 'omnivores' and we have metabolic flexibility, but there are dietary limits beyond which human biology and health are impaired.

We must now extend our gaze to much wider horizons, to understand better the intimate relationships between social-economic priorities, food production, human health and the 'health' of the natural environment. This will require the application of an ecological perspective, to both the social and natural environments. Of particular urgency today, the intensification and extensification of food production - amplified by the competitive pressures of the international food trade, the need to earn foreign exchange, and the growing consolidation and power of 
Nutrition science and food policy classically focus on nutrients in relation to human growth, metabolism, health and disease. With increasing overnutrition in urbanising populations, nutrition research must embrace social and ecological dimensions. Meanwhile, world food production contributes substantially to our increasingly great and global impact on the environment. Both that impact and any related future regional declines in food yields will affect human health. Persisting inequities in access to food and good nutrition must also be addressed. The scope of modern nutrition science should therefore encompass both biomedical nutrition-health issues, and the wider challenges of achieving sustainable food production, greater equity in relation to food and nutrition, and good health prospects for future generations. The fundamental long-term task is to integrate human health with the health of the biosphere.

the food-producing industry - are doing increasing damage to the natural resource base. This perspective leads us away from the prevailing 'productionist' and 'lifesciences integrated' paradigms and towards the alternative 'ecologically integrated paradigm' .

Throughout our agrarian history the balance between population size and food supplies has been subject to the precarious arithmetic of 'Malthusian' subsistence crises. Today, the imminent crisis is of a different ("postMalthusian') and global kind: the limiting factor is not the rate of increase in production but the capacity of the food-producing systems to remain productive. Climate change, biodiversity losses, land degradation, water shortages and fisheries exhaustion pose new constraints at regional and global scales. Yet, given the ongoing increase in world population, along with rising consumer expectations, we may need to double food production by mid-century. Without some remarkable technical breakthroughs, applied in environmentally benign fashion, along with a shift towards healthier and less inputintensive diets, such increases may not be achievable on a sustainable basis.

\section{Discussion}

As global food production escalates to meet both population growth and rising consumer demand, and as terrestrial and marine food-producing ecosystems begin to show the strain of over-exploitation, food policy must engage with the fundamental need to achieve sustainable production of healthy diets. Most of the macroscopic analyses of current global trends concur in the view that, for at least the past quarter-century, humans have been living beyond Earth's capacity to supply, replenish and absorb $^{2}$. Hence, we are not only living off the annual 'interest' (or 'dividend') available from nature, but we are also now eating into the planet's natural capital base. This presents a new category of threat to our future food security, well-being, health and survival. This is a dimension of environmental crisis that could not have been foreseen by Thomas Malthus two centuries ago: his concern was with the limited rate of increase in food production; our modern concern is with a probable decline in productive capacity.

The task of achieving ecological sustainability is compounded by the formidable challenge of also achieving equity. In today's globalising world - wherein the rich-poor wealth divide persists and, on some measures, is worsening ${ }^{3}$ - food policy must also address the complex issue of equity, both within populations and between producer and consumer populations. Sen has written about the issue of disparities in access, or 'entitlement', to food, as a manifestation of socialeconomic inequity ${ }^{4}$. Without fairness in access to food, we increase the probabilities of social disorder, conflicts and exacerbations of terrorism - and iron-fisted responses to it. In addition to economic and social inequities, the issue also encompasses the environmental dimension. For example, as discussed later in this paper, global climate change poses a much greater risk to food yields in tropical and sub-tropical countries than in the generally wealthier temperate regions of the world.

The emerging global environmental predicament in relation to food, water and the natural ecological resource base coincides with a recent growth of interest in understanding human evolutionary origins. This interest has been partly stimulated by the increasing flow of field discoveries revealing more of the hominid evolutionary odyssey. But, more than that, it reflects a fascination with understanding the origins of Homo sapiens and how this species relates to the natural world. This is the culmination of Charles Darwin's dislodging of Man from a self-claimed pedestal that had set humans apart from the rest of that natural world.

Over the past two decades there has been a growing interest in learning about the palaeolithic diet (from fossilised bones and their elemental fingerprints, and by back-projection of the diets of today's hunter-gatherers), 
and in understanding how those ancient diets shaped aspects of human biology ${ }^{5}$. Hence, for example, the idea of the 'expensive tissue' trade-off ${ }^{6}$. This hypothesis argues persuasively that, as mostly plant-eating australopithecines evolved into sometimes-meat-eating early Homo species and then into frequently-meat-eating later Homo species, so an evolutionary trade-off became possible between bowel and brain - both of them being very energy-intensive organs. As the need for a large colonic fermentation chamber receded, so there emerged the expanded possibility for a larger, self-aware, abstractthinking and planning brain. But for that trade-off I would not be writing this paper, and you would not be reading it.

Viewing within these widened horizons, nutrition science and food policy should now apply an integrative approach to understanding health-optimising diets and to the complex ecological task of achieving effective, sustainable, food production. In order to achieve a world nutritional state that is health-supporting, equitable and ecologically sustainable, we can learn much from consideration of the interplay between the evolutionary, environmental and ecological realms. But, more important, an understanding of this interplay is a prerequisite to effectively extending the scope of nutrition science and its capacity for collaborative research engagement.

\section{Nutrients, buman (evolutionary) biology and disease risks}

Animal life on Earth illustrates, in non-subtle fashion, evolutionary opportunism. Plants obtain nutrients from the soil (or aqueous solutions of it) and energy from the sun. Animals then obtain nutrients and energy by eating plants (herbivores) or other animals (carnivores) or both (omnivores). This interdependent system, underwriting all survival, growth and reproduction, has worked for several billion years, during which the environmental demands of plants and animals have been confined to the immediately available natural supplies. Earth's organisms have survived, thrived and speciated while living off nature's 'interest' - that is, the flows (not stocks) of nutrients and energy available from the biosphere on a continuing basis.

Human ecology over the past 20000 to 40000 years has increasingly ventured beyond the confines of this natural system, as cultural and technological developments have supplemented basic human biological and demographic attributes. As with all species, humans tend to expand to the limit of the local environment's 'carrying capacity'. However, humans, uniquely, have found ways to greatly expand that capacity. The story of human food acquisition and production has repeatedly entailed excessive exploitation of the natural resource base, leading to megafauna extinctions, deforestation, soil erosion, salination, water shortages, biodiversity losses (including, now, fisheries depletions), and mobilisation of infections into human populations. Aboriginal Australians, for example, used fire for thousands of years to remodel the landscape, clearing away undergrowth and opening up woodland in which animals thrived - and became easier prey ${ }^{7}$. Via this protracted process, over several millennia, many species of plants and large mammals became extinct.

As human numbers have increased, and as agriculture has widely replaced foraging and hunting, efforts to expand the human-carrying capacity of local environments have tended to become less sustainable. Hence the many historical examples of local ecological declines causing societies to collapse - such as those of Mesopotamia, the Indus Valley, the Mayans, the Anasazi (south-west America), the West Vikings and Easter Islanders $^{8}$. The fratricide in Rwanda in 1994 may have reflected land pressure and food shortage in a fastgrowing population of 8 million reliant on an environmental carrying capacity of approximately 6 million?

There are two types of tension between human evolutionary origins and the later consequences of cultural evolution. The first tension is discussed above: throughout history we humans have tended to push local foodproductive capacity to and beyond sustainable limits. The second tension results from our having developed diets with nutrient and energy profiles that differ significantly from those of the palaeolithic diet and which thus pose risks of biological dysfunction and impaired health. The modern rise of obesity as a mass phenomenon in urban populations is a striking example of this second tension. Put simply, it reflects a ratio of energy intake to energy expenditure that differs greatly from that of our huntergatherer and subsistence farmer forebears. The modern rise of dental decay in children and young adults reflects a large and sustained intake of simple sugars at levels that were just not available in ancestral diets.

Certain more complex examples can help us understand why some populations are better equipped, by evolution, to handle a particular change in diet than are other populations. For instance, with the diffusion of modern processed foods into many cultures and the associated rise of obesity, a divergence has become evident between the various major regional populations in their rates of type 2 diabetes and levels of insulin resistance. Weight for weight, populations of European origin have lower rates of glucose intolerance and diabetes than do other populations (Amerindians, Polynesians, Chinese, Australian Aboriginals, Africans and South Asians). This probably reflects, at least partly, a regional divergence in population genetics due to the different timings and types of agrarian transitions (especially the resultant change in sugar content and glycaemic index) that have occurred around the world, independently of one another, during much of the past 11000 years $^{2,10}$.

That this type of genetic divergence can occur within such a time-span is supported by various other examples of human evolution that have occurred within several thousand years in response to the oft-intense selection 


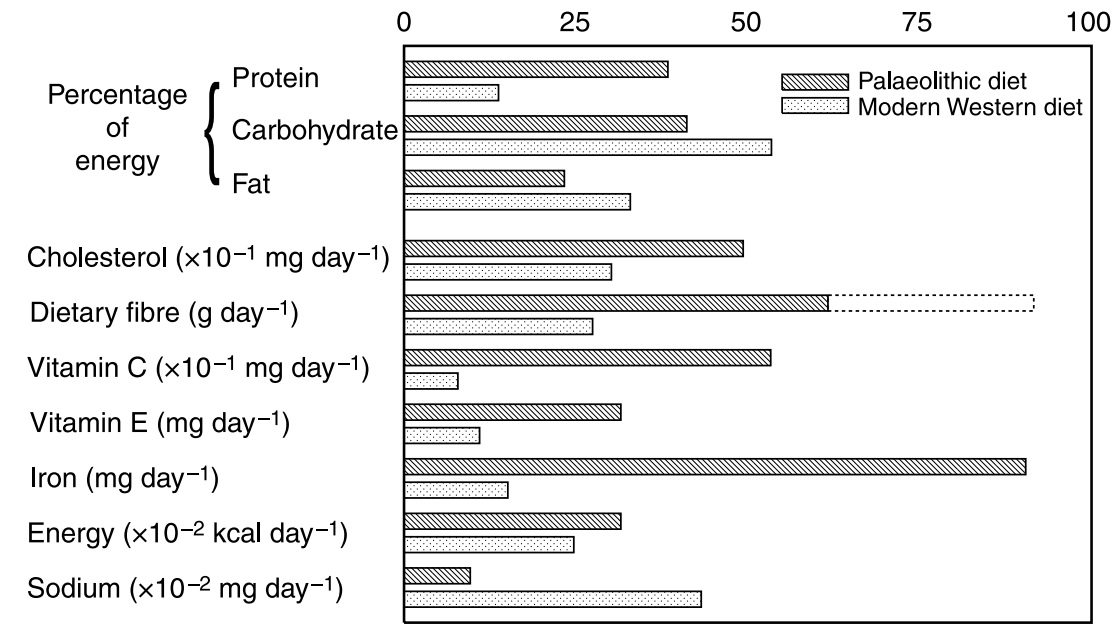

Fig. 1 Comparison of the nutrient profile of the palaeolithic hunter-gatherer diet (estimated) with that of the modern Western diet. (From McMichael $^{2}$, p. 134)

pressures of diet and infectious disease. They include sickle-cell anaemia, thalassaemia, lactose tolerance and gluten enteropathy (coeliac disease) - the last two also reflecting regional differences in prevailing diets ${ }^{11}$.

There have been great changes in nutrient profile between the palaeolithic diet consumed by archaic and modern Homo sapiens over the past several hundred thousand years and that of today's societies. The main dietary differences are shown in Fig. 1, which draws on several sources ${ }^{2,12}$. We can also note several other major differences. First, the average duration of breastfeeding differs by an order of magnitude between hunter-gatherer and modern Western cultures - approximately 3 years versus 3-4 months, respectively ${ }^{13,14}$. Second, huntergatherers typically eat over 100 different plant species, many of them seasonally, while the usual agrarian diet contains only $10-15$ species of plants ${ }^{15}$.

Whatever moral or health-related views one holds about carnivory, it is clear that most hunter-gatherer populations (with their bigger brains and more compact colons, acquired over the past 1-2 million years) consumed much meat. Indeed, meat intake often accounted for up to twothirds of daily energy intake, and provided a high-grade nutrient source. Modern diets contain less meat and more total fat and carbohydrate (which, further, is increasingly weighted towards simple sugars). Dietary fibre, salt, trace elements and vitamins all display marked differences, towards levels that we would now associate with increased risks to health.

There has been a very important health-related debate about dietary fat intake, blood lipids and the risks of disease (especially cardiovascular disease and cancer). This scientific debate, over the past four decades, has become increasingly sophisticated and complex. Only in its latter stage has it looked beyond conventional empirical evidence to consider what might also be learnt from human biological evolution. This is illustrated further via the example of 'fish oils' in Box 1.
The domestication and then selective cultivation of wild cereal grasses evolved over several thousand years (at a time when climate and environment were changing, postglaciation). The fossil evidence indicates that, as early farming and settled living became an integral part of human ecology, the stature of these early agrarians decreased by around $5 \mathrm{~cm}$ relative to their immediate hunter-gatherer predecessors $^{15}$ - although there are inconsistencies in the available data ${ }^{16}$. Apparently, biological growth potential was no longer being realised, either because nutrient and energy intakes in the pre-adult life of these early villagefarmers were inadequate or because of the growthretarding effect of childhood infections. Analysis of bones suggests that dietary inadequacy and some specific nutrient deficiencies were largely to blame.

Over the ensuing millennia further loss of stature occurred, such that by the early Bronze Age, around 4500 years ago, agrarians were approximately $12 \mathrm{~cm}$ shorter than their genetically similar hunter-gatherer ancestors. Interestingly, modern Western populations are only just now regaining that ancestral palaeolithic stature, having gained up to $10 \mathrm{~cm}$ in the last two, better-fed centuries ${ }^{2}$. (However, tall as we might now be, we are now paying another price, in later adulthood, for the dietary abundance and accompanying nutrient imbalances of the modern diet.)

The argument about the evolutionary fit between human biology and the palaeolithic diet does not necessarily mean that the modern diet is generally hazardous to health. Undoubtedly, the modern diet poses many well-documented risks to health, especially through its contributions to the 'degenerative' diseases of later adulthood. But it also confers benefits, particularly the two that follow.

First, food production in the world's high-income societies is now more resilient against the vicissitudes of nature: food insecurity has largely disappeared in those populations, and famines have not occurred in Western 
societies for 150 years. The introduction into Europe of the potato, from South America, around four centuries ago provided an additional, relatively environmentally resilient, buffer against food shortages.

Second, relatedly, modern trading patterns and levels of wealth enable year-round supplies of health-benefiting fruits and vegetables. For example, the inter-seasonal variation in vitamin $\mathrm{C}$ intake varies little in the UK, but in the 1980s and 1990s it still varied six-fold in some Eastern European populations that were not yet integrated into the pan-European (and beyond) food trade ${ }^{17}$.

\section{Trends in world food production}

Total food production has almost tripled since the 1960s, while the world population has approximately doubled. This has mostly resulted from gains in cereal grain yield, including improved grain yields achieved via the Green Revolution. This has depended on higher-yield 'dwarf' strains and more intensive inputs of energy and chemicals - although those inputs have often been at the expense of soil loss and damage and depletion of water resources. Meanwhile, globally, the annual rate of expansion of cropland has declined, and around the world little additional good land remains to be recruited. Globally, the average per-person total calorie production has, so far, increased a little faster than has population size, much assisted by expansion of calorie-dense oil crops.

On any reasonable ecological analysis, however, there must be limits (at least in the absence of remarkable Great Leaps Forward in food production methods). Some commentators now wonder if we are starting to see evidence of over-use of agro-ecosystems for grain farming. Improvements in yield, especially for cereal grains, have slowed over the past decade ${ }^{18-20}$ and, globally, the annual increase in grain harvest has been falling behind annual population increase during 1996-2003 (Fig. 2). Cereal grains (rice, wheat, maize) are an important index of food adequacy since, worldwide, they account for around half of all food energy. While much grain is consumed directly, an increasing proportion (currently about one-third) is consumed via its rather inefficient conversion to meat (chicken, pork and, especially, beef), eggs and dairy products (see Box 2).

The downturn during 1996-2003 is undoubtedly multicausal. The main likely contributors include the switch from growing grain to other crops in some regions, government-subsidised idling of grain-farming land in the

\section{Box 1 - Omega-3 fatty acids: the rediscovery of an ancient, human biology-attuned nutrient}

The many - and seemingly magical - health benefits of 'fish oils' can be much better understood within an evolutionary framework. Animal experimental studies and human epidemiological studies have shown that these unsaturated long-chain fatty acids (eicosapentaenoic acid and docosahexaenoic acid) have beneficial effects on blood lipid profile (raising the level of highdensity lipoprotein cholesterol - the 'good' cholesterol), blood clotting tendency, blood pressure, cardiac muscle rhythmic stability (against oxygen deprivation), insulin resistance and aspects of immune system function (e.g. apparently lessening the risks of childhood asthma $)^{1-3}$. They are also known to be beneficial to infant and child brain growth and maturation, and may contribute to brain function and durability in adults.

Despite the popular name 'fish oils', the unsaturated long-chain omega-3 $(n-3)$ fatty acids are widespread in plant foods (e.g. walnuts and flax seeds) and in the meat of game animals, as well as in fish and other seafood. They, plus the unsaturated $n-6$ fatty acids (mostly from plant sources), were much more prominent in the diet of our hunter-gatherer forebears than were saturated fats. In that palaeolithic diet, there were approximately equal amounts of the $n-6$ and $n-3$ fatty acids. Today, the dietary ratio of $n-6$ to $n-3$ fatty acids varies greatly. This is well illustrated by the following approximate ratios: Western societies $=9: 1$; Japanese $=3: 1$; Inuit (Eskimos) and other huntergatherers $=1: 1^{4}$

Human groups were never far from waterways or coasts and much migration is likely to have occurred along rivers and around coastlines. Archaeological studies indicate that aquatic foods were more prominent in the palaeolithic human diet than was previously thought. During most of hunter-gatherer existence, diets must have contained substantial unsaturated $(n-3)$ fatty acids from aquatic foods, game animals, seeds and nuts. We can reasonably conclude, then, that human biology is evolutionarily well attuned to these $n-3$ fatty acids.

\section{References}

1 British Nutrition Foundation. n-3 Fatty Acids and Health, Briefing Paper. London: British Nutrition Foundation, 1999.

2 Schmidt EB, Skou H, Christensen J, Dyerberg J. n-3 fatty acids from fish and coronary artery disease: implications for public health. Public Health Nutrition 2000; 3: 91-8.

3 Franco OH, Bonneux L, de Laet C, Peeters A, Steyerberg E, Mackenbach J. The Polymeal: a more natural safer and probably tastier (than the Polypill) strategy to reduce cardiovascular disease by more than $75 \%$. British Medical Journal 2004; 329: 1447-50.

4 McMichael AJ. Human Frontiers, Environments and Disease. Cambridge: University Press, 2001. 
Integrating nutrition with ecology

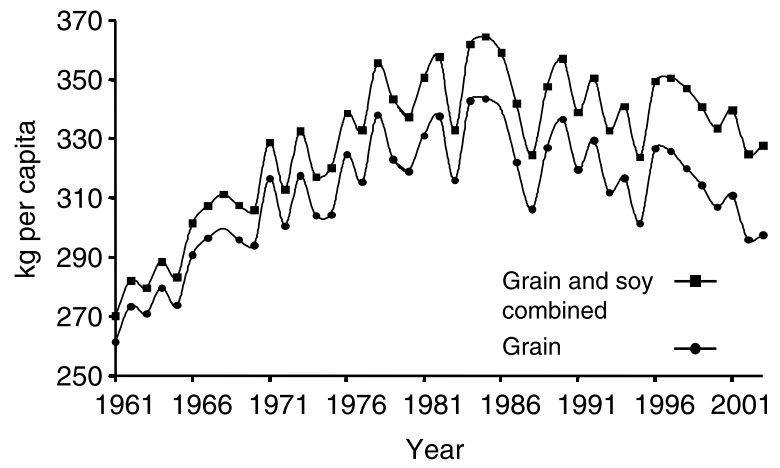

Fig. 2 Global per capita grain and soy production, 1961-2003. Peak production occurred in 1985. Since then the decline in per capita grain production has been partly compensated by increased soy production. Soy is an increasingly important form of animal feed. (Source: Butler, see Fig. 4.3 in ref. 1.) (Note: preliminary figures for grain-plus-soy in 2004 indicate a rebound, perhaps to around the 1997-8 level.) Raw data from the Food and Agriculture Organization and United Nations Population Division

USA and some European countries, the downturn in agriculture in Russia and other former USSR countries since 1990, the widespread decline in soil fertility and productive land area over the past several decades ${ }^{18}$ and, perhaps, the early impacts of climate change, particularly by affecting soil moisture and temperature-dependent photosynthesis (see also below) ${ }^{21}$.

\section{Trends in food availability: equity issues}

In hunter-gatherer societies food is typically procured locally and is then consumed promptly, via sharing, since there is little opportunity for storage. However, since the advent of agriculture humans have generally done better at producing than sharing food: poverty and food insecurity have burdened most of humankind in settled agrarian-based societies throughout history. While the proportion of hungry and malnourished people in the world is slowly declining, in absolute terms there remain an estimated 840 million undernourished people $\mathrm{e}^{22}$. Of these, $95 \%$ are in middle- and low-income countries (and around 60\% of these are in Asia). Meanwhile - seemingly a distasteful irony - the prevalence of obesity is now increasing in middle-class urban populations everywhere.

There has been a recent increase in the maldistribution of global dietary energy intake. Figure 3 shows that the distribution in the 1990s had become more unequal than in the 1980s. The distribution for the 1990s is more obviously bimodal (with a strong peak in the proportion of persons with low intake, around $2000 \mathrm{kcal}$ daily) than in the 1980s, when the distribution was 'flatter'.

An important question here is whether this re-emerging international maldistribution is related to the impending limits to continued gains in productivity (as hinted at by Fig. 2, indicating a recent decline in per capita production of grains), the latter occurring because of a combination of climatic, ecological and social factors. Indeed, the world's

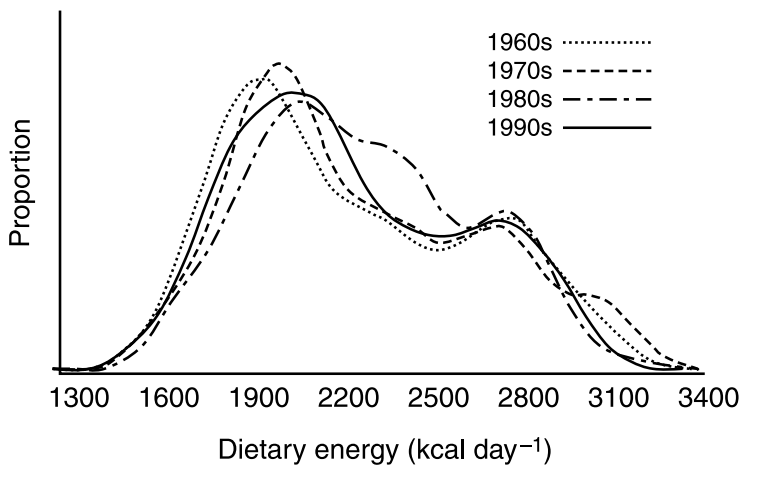

Fig. 3 Distribution of per capita dietary energy by decade. Note the bimodality of the 1960s and 1970s distributions. The 'flatter' pattern of the 1980s distribution indicates that more of the world population was being fed adequately. However, the 1990s distribution reverts to the earlier bimodal pattern of 1960s and 1970 s. (Source: adapted from Wang et al. ${ }^{23}$ )

poor appear to face a double penalty: first, there is reduced grain per person, and, second, more of this reduced per capita supply is being fed to animals (i.e. used as 'feed', not 'food').

Together, these factors provide a plausible explanation for the recent shift to a more unequal, bimodal, distribution of daily per capita dietary energy, in Fig. 3 and, if correct, this trend may worsen during this current decade. Further, it is likely that little of this extra (grainfed) meat is consumed by the poor. In fact this extra meat production may also harm the poor, by reducing the price of factory-farmed meat such that small-scale meat producers cannot compete (C Butler, personal communication).

\section{Environmental stresses and sustainable food production}

By definition, agriculture alters ecosystems and the biogeophysical environment. In the views of some commentators, ongoing trends in agricultural activity may cause more global environmental damage over coming decades than will 'new' changes such as global climate change $e^{24,25}$. Already, approximately one-third of the world's fertile soil is moderately or severely damaged by erosion, salination, water-logging, chemicalisation, loss of organic material and compaction ${ }^{26,27}$. The spread of irrigation typically exacerbates salination and waterlogging. It is also depleting many of the world's great aquifers (fossil water), and this now poses looming problems in Northern China, the American Midwest and Northwest India.

The chemicalisation of soil and waterways will increase, especially as the use of nitrogenous fertiliser (and other anthropogenic sources of biologically active, 'fixed', nitrogen) increases. This process contributes to soil acidification and raises nitrate levels in ground, surface and coastal waters ${ }^{26,28}$. Nitrogenous fertilisers also 


\section{Box 2 - Sustainable livestock production}

The domestication of animals as a food source, millennia ago, made them easier to catch and kill, and to exploit their reproductive cycle (eggs and milk). This greatly helped to ensure supply. But human culture and technology rarely stand still and, under the modern stimuli of industrialisation and competitive free-trade, the breeding and growing of livestock have much intensified. This generates four major problems: first, seriously impaired animal welfare, including heightened disease incidence; second, heightened pressures on the environment; third, substantial energy losses due to the diversion of cereal grains from humans to animals; and fourth, diverse (and often unexpected) risks to human health. The latter include the generation of antibiotic-resistant bacteria and the mobilisation of infectious disease agents (e.g. new influenza virus strains and other avian viruses from pig-duck-human contacts in Southern China and high-density chicken farming in Southeast $\mathrm{Asia}^{1}$ and the UK's 'mad cow disease' episode and consequent variant CreutzfeldtJakob disease in humans ${ }^{2}$ ).

Globally, as the per-person production of cereal now appears to be declining, the per-person production of meat is continuing its four-decades-long 60\% rise $^{3}$. Meat is widely viewed as a desirable, high-quality component of diet, and hence an increase in meat consumption is a central feature of the 'nutrition transition' ${ }^{4}$. However, producing sufficient, not to mention excessive, meat for a future global urban population of 5-6 billion poses major challenges to environmental sustainability.

\section{Industrial animal production}

Modern 'industrial' meat production requires very high inputs of energy, water, cereal grains and ('growthpromoting') antibiotics, and it does much damage to local environments (effluent, chemical runoff) while also contributing to global climate change (via methane release from livestock, from both ends). In Australia, where the English culinary culture was transplanted two centuries ago without reference to local environment, cattle and sheep farming has done widespread damage to soils, pastures and waterways. It would be both environmentally beneficial and health-promoting if those cloven-hoofed domesticates were substantially replaced by kangaroos (a plentiful source of low-fat meat $)^{5}$.

The statistics for food-energy losses and water requirements for production of feed-lot and factoryfarmed livestock are impressive ${ }^{3,6}$. To produce $1 \mathrm{~kg}$ of feed-lot beef requires around $9 \mathrm{~kg}$ of cereal grain (e.g. corn); for pork the approximate ratio is $4: 1$, for chickens 2:1. Beyond those statistics is the issue of $w$ bo bears the losses. The answer is that they are mostly borne by poorer populations in lower-income countries striving to generate foreign exchange by exporting feed-grains - rather than growing foodgrains for local consumption.

Events in East and Southeast Asia in recent years have highlighted some other health-endangering aspects of the rearing, capture and sale of animals for food. For millennia, small farms accommodated mixed species living closely with humans - goats, pigs, cattle, ducks, geese, chickens, and perhaps a water buffalo or a donkey - and accordingly there was much animal-toanimal and animal-to-human transfer of (often novel) infectious agents.

\section{Danger of infection}

As mentioned above, the widespread duck-pighuman small-farm complex in Southern China is implicated in the generation of variant influenza virus strains. Cross-infection also occurs when animal species are raised separately but are sold together in the market place. The 1997 outbreak of avian influenza in Hong Kong occurred in mixed markets, where live chickens, quail and ducks were stacked together in close quarters with humans ${ }^{7}$. The liking, widely evident in that part of the world, for eating exotic animal species also exacerbates the risk of exposure to infections not previously encountered. Indeed, this situation probably triggered the severe acute respiratory syndrome (SARS) epidemic, in which (wild) palm civet cats, traded across national borders, were the prime suspect as the source of the new corona virus that caused SARS ${ }^{1}$.

\section{References}

1 Weiss R, McMichael AJ. Social and environmental risk factors in the emergence of infectious diseases. Nature Medicine 2004; 10: S70-6.

2 McMichael AJ. Bovine spongiform encephalopathy: its wider meaning for population health. British Medical Journal 1996; 312: 1313-4.

3 Tilman D, Cassman KG, Matson PA, Naylor R, Polasky S. Agricultural sustainability and intensive production practices. Nature 2002; 418: 671-7.

4 Popkin BM. The nutrition transition in the developing world. Development Policy Review 2003; 21: 581-97.

5 Flannery T. The Future Eaters. Chatswood, NSW: Reed Books, 1994.

6 McMichael AJ. Planetary Overload: Global Environmental Change and the Health of the Human Species. Cambridge: Cambridge University Press, 1993.

7 Webster RG. Wet markets - a continuing source of severe acute respiratory syndrome and influenza? Lancet 2004; 363: $234-6$ 
increase the soil emission of nitrogen oxides, resulting in an increase in the formation of ozone in the lower atmosphere - an air pollutant that has adverse impacts on human cardiorespiratory health, crops and natural ecosystems. Around one-third of the world's cereal crops is exposed to damaging levels of ozone in the view of Tilman and colleagues ${ }^{27}$.

Various of the global environmental changes now becoming evident are likely to affect food production (see Box 3). In addition to climate change, the other incipient large-scale environmental changes that would affect food production include the accelerating loss of biodiversity (with knock-on effects on crop and livestock pest species), changes in several of the great elemental cycles (nitrogen, sulphur and phosphorus), and land degradation and freshwater shortages caused by expanding agricultural, pastoral and industrial demand. Further, many of these processes will interact with one another. For example, crop infestations by pests may be amplified by changes in climatic conditions, weakened photosynthesis and plant biology due to increased soil micronutrient deficiencies and ambient ultraviolet irradiance, the depletion of predator species, and water shortages.

Given that we must find ways to produce more food, there is a fundamental question as to whether this will rely primarily on gains in yields or on increases in the land area farmed $^{29}$. In the view of Tilman et al. ${ }^{27}$ : 'crop and livestock production must increase without an increase in the negative environmental impacts associated with agriculture, which means large increases in the efficiency of nitrogen, phosphorus and water use, and integrated pest management that minimizes the need for toxic pesticides. In reality, achieving such a scenario represents one of the greatest scientific challenges facing humankind...' The results of one recent study suggest that farming, at lower yield levels on more cropland, is a greater threat to bird species (the best known taxon for monitoring biodiversity) than is intensive high-yield farming on less land. Currently the adverse biodiversity impacts of lower-yield farming look set to increase, especially in middle- and low-income countries $^{30}$.

To provide sufficient food for a forecast population of 89 billion people by 2050 will probably require both strategies: the intensification of agriculture, and the recruitment of more land (with inevitable loss of other, non-food-producing, ecosystem services). Since both the intensification and expansion of agriculture also increase the risks of various known and newly emerging infectious diseases, consideration of population health would improve policies about future agricultural policies and practices.

The promise of genetically modified (GM) food species, while potentially great, remains clouded by unresolved uncertainties about the genetic, nutritional and ecological consequences. The genetic modification of food species (an intrinsically very clever achievement of our bigbrained species) should be a co-operative public-private partnership, with agreed environmental, social and public health objectives. Priority should be given to nutritional needs in food-insecure populations. Despite widespread anxieties over GM technology, there are, starkly, two alternative strategies to achieve increased production: (1) change the landscape to enhance crop yields, or (2) change the cultivars to fit them to the existing landscape and thus enhance their yield. We have already done too much of the former.

So, how best to proceed? In the first instance, a judicious combination of efficient use of fertilisers, pesticides and water, along with GM-enhanced responsiveness of plants to sustainably managed agricultural landscapes, would be an important step. The other essential step is to increase the population's food literacy and to thereby re-direct food demand and consumption towards health-supporting and environmentally benign foods.

\section{Conclusion}

All food derives from the natural world. Its production is subject to the limits of ecological systems and to the vicissitudes of weather, pests and diseases. In nature, there is a strong coupling of food sources with biological evolution in the animal kingdom: human biology reflects millennia of evolutionary winnowing by dietary selection pressures. Obtaining sufficient food has been the central task in all societies, a task that eventually led our huntergatherer ancestors towards the agrarian diet. Hence, the evolution of human biology and of human society have both been intimately shaped by the types and amounts of food available.

For most of human agrarian history the balance between population demands and food supplies has displayed the precarious arithmetic that underlies Malthusian subsistence crises. Life in today's rich countries - a tiny and historically unusual part of the total human experience - can easily mislead us about the future security of food supplies. As the scale of the world feeding task mounts, and as urban consumer preferences for animal-based foods grow, so too, currently, does our reliance upon environmentally damaging modes of food production.

If we are to feed the expanding human population during this twenty-first century adequately, safely and equitably, then we must strive to:

- Constrain world population growth.

- Develop ecologically sustainable methods of food production. Selectively bred high-yielding strains may yet provide another round of yield gains. Since this would be reliant on sufficient fertiliser and water, both will have to be used much more efficiently. Genetic modifications (for example, insertion of the insecticide- 
producing $B t$ gene), wisely used, may assist these efficiency gains.

- Recognise the human evolutionary basis for the choice of an optimal nutrient profile, based on a diversity of foods:

- Encourage consumption of fresh fruit and vegetables, thereby reducing consumption of energy- and materials-intensive processed foods and animal foods.

- Discourage the view that meat is the mainstay of an affluent diet. For dietary optimisation the level of perperson meat consumption need only be moderate.

- Achieve greater equity in world trade; encourage economic development that allows for local production of staple foods as opposed to emphasising export crops; and seek fairer and more efficient food distribution systems.

- Recreate the conditions that support viable small-scale, community-based farming. Centralised large-scale approaches to agribusiness in low- and middle-income countries have done widespread damage to the social fabric of local communities, livelihoods, well-being and health.
We may already have pushed some of the world's foodproducing systems to, or in some cases beyond, their limits. Yet, given the ongoing increase in world population, and the rise in consumer expectations, we will need to at least double world food production by around 2050. Without remarkable new technical breakthroughs, coupled with the environmentally benign food production methods, such increases may not be achievable on a sustainable basis.

While most of the world's current concerns have to do with terrestrial food production, there is a classic 'Malthusian' crisis emerging in the oceans, where modern harvesting technologies have been combined with the ancient ethos of the hunter-gatherer: 'Mining the sea at the present rate will result in the extinction of fish species and the destruction of whole ecosystems, with unforeseen consequences $^{25}$.

In the early 1990s I wrote: 'Meanwhile, we are burning the candle at both ends: while human populations continue to grow, particularly in areas where soils are relatively less fertile, so the land resource base used for farming and grazing is degrading - and the supply of freshwater, both surface and subterranean, is dwindling.

\section{Box 3 - Global climate change and food production}

Historically, climatic fluctuations have repeatedly caused food shortages, famine, deaths and social unrest ${ }^{1}$. The climate is less irregular in Europe and North America than in most other regions, particularly tropical and sub-tropical regions. Floods and famines in China and famines in India have been notorious killers over the centuries.

Under climate change conditions, food yields will be affected by changes in average temperature and patterns of annual rainfall ${ }^{2,3}$. Higher temperatures may reduce crop yields in tropical regions and excessive heat may harm grain flowering. A study at the International Rice Research Institute, in the Philippines, found that the yield of rice fell by $10 \%$ for every $1^{\circ} \mathrm{C}$ increase in the mean night-time minimum temperature during the dry season ${ }^{4}$.

Recent studies modelling the future impact of climate change on food yields forecast a 'modest' overall net decline. However, the models indicate a world of 'winners and losers', there being great regional variation in the impact ${ }^{2}$. Higher temperatures may reduce crop yields in tropical regions. Most of the losers tend to be in low-latitude countries where food insecurity is already widespread (including South Asia, parts of the Middle East, North Africa, much of Sub-Saharan Africa and Central America). Irrigationdependent agriculture would be vulnerable to reduced rainfall, exacerbated by heightened evaporative losses. Less predictably, climatic changes would influence the ecology of plant pests and pathogens. Further, great damage would accrue from the likely increase in floods, droughts, storms and fires under climate change.

Sea-level rise is another environmental consequence of global warming. A half-metre rise, which could occur by 2100 because of climate change, would approximately double the number who experience flooding annually from around 50 million to 100 million (at today's population). Some of the world's coastal arable land and fish-nurturing mangroves would be damaged by sea-level rise. Rising seas would also cause salination of coastal freshwater aquifers, particularly those beneath small islands.

\section{References}

1 Bryson RA, Murray TJ. Climates of Hunger: Mankind and the World's Changing Weather. Madison, WI: University of Wisconsin Press, 1977.

2 Rosenzweig C, Tubiello FN, Goldberg R, Mills E, Bloomfield J. Increased crop damage in the US from excess precipitation under climate change. Global Environmental Change 2002; 12: 197-202.

3 Lobell DB, Asner GP. Climate and management contributions to recent trends in US agricultural yields. Science 2003; 299: 1032.

4 Peng S, Huang J, Sheehy JE, Laza RC, Visperas R, Zhong $\mathrm{X}$. Rice yields decline with higher night temperature from global warming. Proceedings of the National Academy of Science 2004; 101: 9971-5. 
Further, we have begun to overfish the seas' 31 . Now we are in the twenty-first century, and it may yet provide the first global test of Thomas Malthus' ideas about the potential mismatch between the growth trajectories of human populations and food production. More worryingly, though, the great advances in food-producing technologies that averted earlier Malthusian predictions, during the nineteenth and twentieth centuries, have helped create a contemporary situation wherein, because of our massive impacts on environmental resources and ecosystem integrity, we must now have post-Malthusian concerns about the actual sustainability of future food production.

\section{References}

1 Lang T, Heasman M. Food Wars. The Battle for Mouths, Minds and Markets. London: Earthscan, 2004.

2 McMichael AJ. Human Frontiers, Environments and Disease: Past Patterns, Uncertain Futures. Cambridge: University Press, 2001.

3 Butler CD. Inequality, global change and the sustainability of civilisation. Global Change and Human Health 2000; 1(2): 156-72.

4 Sen A. Poverty and Famines. An Essay on Entitlement and Deprivation. Oxford: Oxford University Press, 1981.

5 Cohen M, Armelagos G. Paleopathology at the Origins of Agriculture. London: Academic Press, 1984.

6 Wheeler P, Aiello L. The expensive tissue hypothesis. Current Anthropology 1995; 36: 199-222.

7 Flannery T. The Future Eaters. Chatswood, NSW: Reed Books, 1994.

8 Diamond J. Collapse: How Societies Choose to Fail or Succeed. London: Allen Lane, 2005.

9 Andre C, Platteau JP. Land relations under unbearable stress: Rwanda caught in the Malthusian trap. Journal of Economic Behavior E Organization 1998; 34: 1-47.

10 McMichael A. Diabetes, ancestral diets and dairy foods: an evolutionary perspective on population differences in susceptibility to diabetes. In: Macbeth $\mathrm{H}$, Shetty $\mathrm{P}$, eds. Ethnicity and Health. London: Taylor \& Francis, 2001; $133-46$.

11 Cavalli-Sforza I, Menozzi P, Piazza A. The History and Geography of Human Genes. Princeton, NJ: Princeton University Press, 1994.

12 Eaton S, Konner M. Paleolithic nutrition. A consideration of its nature and current implications. New England Journal of Medicine 1985; 312: 283-9.

13 Wickes I. A history of infant feeding. Part 1. Primitive peoples: ancient works; renaissance writers. Archives of Disease in Childhood 1953; 28: 151-8.

14 Eaton S, Pike M, Short R, Lee NC, Trussell J, Hatcher RA, et al. Women's reproductive cancers in evolutionary context. Quarterly Review of Biology 1994; 69: 353-67.

15 Strassman B, Dunbar R. Human evolution and disease: putting the Stone Age in perspective. In: Stearns S, ed. Evolution in Health and Disease. Oxford: Oxford University Press, 1999; 91-101.

16 Wood J, Milner G, Harpending H, Weiss K. The osteological paradox: problems of inferring prehistoric health from skeletal samples. Current Anthropology 1992; 33: 343-70.

17 Powles J, Day N, Sanz M, Bingham S. Protective foods in winter and spring: a key to low vascular mortality? [letter]. Lancet 1996; 348: 898-9.

18 Programme UNE. Global Environment Outlook (3). Nairobi, Kenya: United Nations, 2002.

19 WEHAB. A Framework for Action on Biodiversity and Ecosystem Management: The WEHAB Working Group, 2002.

20 Tilman D, Fargione J, Wolff B, D'Antonio C, Dobson A, Howarth R, et al. Forecasting agriculturally driven global environmental change. Science 2001; 292: 281-4.

21 Peng S, Huang J, Sheehy JE, Laza RC, Visperas RM, Zhong X, et al. Rice yields decline with higher night temperature from global warming. Proceedings of the National Academy of Sciences of the USA 2004; 101: 9971-5.

22 Food and Agriculture Organization (FAO). The State of Food Insecurity in the World. Rome: FAO, 2004.

23 Wang W, Taniguchi K, eds. Nutrition Intake and Economic Growth. Studies on the Cost of Hunger. Rome: Food and Agriculture Organization, 2003.

24 Greenland D, Gregory PJ, Nye PH. Land resources and constraints to crop production. In: Riley R, ed. Feeding a World Population of more than Eight Million. Oxford: Oxford University Press, 1998.

25 Trewavas A. Malthus foiled again and again. Nature 2002; 418: $668-70$.

26 Criss RE, Davisson ML. Fertilizers, water quality, and human health. Environmental Health Perspectives 2004; 112: A536.

27 Tilman D, Cassman KG, Matson PA, Naylor R, Polasky S. Agricultural sustainability and intensive production practices. Nature 2002; 418: 671-7.

28 Fields S. Global nitrogen: cycling out of control. Environmental Health Perspectives 2004; 112: A556-63.

29 Trewavas A. The population/biodiversity paradox. Agricultural efficiency to save wilderness. Plant Physiology 2001; 125: $174-9$.

30 Green RE, Cornell SJ, Scharlemann JP, Balmford A. Farming and the fate of wild nature. Science 2005; 307: 550-5.

31 McMichael A. Planetary Overload: Global Environmental Change and the Health of the Human Species. Cambridge: University Press, 1993; 234. 